\title{
STUDY ON EFFECT OF COGNITIVE INTERVENTION ON MATHEIMATICAL DIFFICULTIES OF CHILDREN IN TELANGANA.
}

KEY WORDS: Cognitive, Intervention, Mathematical.

\section{S. Suresh Babu} Lecturer in Education, Navabharathi College of Education. Hyderabad.

The focus of this article is intervention for primary school students with mathematics difficulties at third grade students. Government schools from Telangana. GLAD (Grade level assessment device) skills test were used to assess their mathematical difficulties in primary school students. Total 100 sample was selected from two different government schools. 6 months' cognitive intervention programmes were implemented to enhance the mathematical performance of primary school students. Paired t-test was used for analysis. The study results revealed that there was no significant difference between pre-test score of control and experimental group of primary school student. Intervention results showed that there was significant difference between post test scores of control and experimental group of primary school students.

\section{INTRODUCTION}

Mathematics is a branch of human knowledge which has received a lot of attention in recent years. Power has been currently gained on the basis of technology, which heavily rests on mathematics. Problems in learning mathematics appear at a very early stage in children, but mostly in elementary school, and then continue up to high school (Gersten, Jordan, \& Flojo, 2005). Math disability has been addressed by many researchers from various aspects. Many have attributed math disability to information processing inefficiency, yet others have attempted to draw a dividing line between such educational progress problems and cognition ( Geary, Brown, \& Samaranayake, 1991). Moreover, Corno \& Mandinach (1983) have reported cognitive involvement as an effective cognitive factor in educational progress. Low cognitive involvement is defined with surface processing strategies (such as mental reviewing) and high cognitive involvement with deep processing strategies (such as organizing). Accordingly, some researchers have studied the influence of effective factors on educational performance and have shown that educational performance is influenced by executive functions ( Best, Miller, \& Naglieri, 2011).

Mathematics is a branch of human knowledge which has received a lot of attention in recent years. Power has been currently gained on the basis of technology, which heavily rests on mathematics. Problems in learning mathematics appear at a very early stage in children, but mostly in elementary school, and then continue up to high school (Gersten, Jordan, \& Flojo, 2005). Math disability has been addressed by many researchers from various aspects. Many have attributed math disability to information processing inefficiency, yet others have attempted to draw a dividing line between such educational progress problems and cognition ( Geary, Brown, \& Samaranayake, 1991). Moreover, Corno \& Mandinach (1983) have reported cognitive involvement as an effective cognitive factor in educational progress. Low cognitive involvement is defined with surface processing strategies (such as mental reviewing) and high cognitive involvement with deep processing strategies (such as organizing). Accordingly, some researchers have studied the influence of effective factors on educational performance and have shown that educational performance is influenced by executive functions ( Best, Miller, \& Naglieri, 2011).

Mathematics is a branch of human knowledge which has received a lot of attention in recent years. Power has been currently gained on the basis of technology, which heavily rests on mathematics. Problems in learning mathematics appear at a very early stage in children, but mostly in elementary school, and then continue up to high school (Gersten, Jordan, \& Flojo, 2005). Math disability has been addressed by many researchers from various aspects. Many have attributed math disability to information processing inefficiency, yet others have attempted to draw a dividing line between such educational progress problems and cognition (Geary, Brown, \& Samaranayake, 1991). Moreover, Corno \& Mandinach (1983) have reported cognitive involvement as an effective cognitive factor in educational progress. Low cognitive involvement is defined with surface processing strategies (such as mental reviewing) and high cognitive involvement with deep processing strategies (such as organizing). Accordingly, some researchers have studied the influence of effective factors on educational performance and have shown that educational performance is influenced by executive functions (Best, Miller, \& Naglieri, 2011).

Mathematics (math) is not only the science of numbers, but also is used in everyday life from calculating time and distance, to handling money and analysing data to make decisions in financial planning and insurance purchasing, and is essential in the STEM (science, technology, engineering and math) fields. Infants have an innate capacity for "numerosity" or the number of things. In early childhood, counting is learned to bridge this innate capacity to more advanced math abilities like arithmetic facts and concepts. Math is a core subject taught in primary and higher education, which builds a foundation of math skills for real life situations. Numeracy is the knowledge and skills required to effectively manage and respond to the mathematical demands of diverse situations, and is a necessary skill in both blue-collar and professional work places.

Cognitive strategy that can be used to teach primary-level students with mathematics difficulties and LD how to solve primary-level word problems. The MSI is part of the Early Numeracy Intervention program (Bryant, Pfannenstiel, \& Bryant, 2014), which was validated in studies showing overall positive findings (see Bryant et al., 2011, for more information about the findings). Additionally, metacognitive strategies (i.e., "thinking about thinking"), such as self-regulation, help students with "planning, monitoring, and modifying" (Pintrich \& DeGroot, 1990, p. 33) their approach to solving a problem. Metacognitive strategies paired with cognitive strategies (i.e., read, plan, solve) have been shown to increase students' understanding and their ability to solve problems (Montague et al.,2011).

\section{Review of Literature}

VarelaS.B et., al (2020) studied Effectiveness of digital-based interventions for children with mathematical learning difficulties: A meta-analysis random effects meta-analysis indicated that digital-based interventions generally improved mathematical performance (mean ES $=0.55$ ), though there was a significant heterogeneity across studies. There was no evidence that videogames offer additional advantages with respect to digital-based drilling and tutoring approaches. Moreover, effect size was not moderated when interventions were delivered in primary school or in preschool. 
Fatimah.S et.,al (2020) studied Students' Mathematical Problem-Solving Ability Based On Teaching Models Intervention And Cognitive Style. The MPSA test finds out that there are interaction effect teaching models and cognitive styles on students' MPSA, as well as a significant difference in MPSA students who study through the CORE RME model, CORE model, and Conventional model. Based on cognitive style, between students who study through CORE RME model, CORE model, and Conventional model found that there was no significant difference in MPSA between FI students. Furthermore, there were significant differences in MPSA between FD students and also MPSA of FI students better than MPSA FD students. Therefore, teaching models and student cognitive styles are very important to be considered in the learning process, so students are able to solve mathematical problems.

Sarah R.P et., al (2019) Studied A Synthesis of Elementary Mathematics Interventions: Comparisons of Students with Mathematics Difficulty with and Without Comorbid Reading Difficulty. The study revealed that intervention effects were strong for students with $M D+R D$ and variable for students with $\mathrm{MD}$-alone. In the three studies directly comparing the performance of students with $M D+R D$ versus $M D$-alone, we noted differential patterns of performance. To tailor interventions to student need, more research must be conducted to understand whether students with MD with variable reading profiles respond differentially to mathematics intervention.

Maryam.P et., al (2018) studied Mathematics Performance of the Primary School Students: Attention and Shifting. The ANOVA and t-test showed that the low-achieving group stood significantly lower than the high-achieving group in shifting, which mirrors the effect of this function in math performance of the students. However, there was no significant difference between the two groups in terms of attention.

Radhika.S and Kavitha.V.K (2017) studied Effect of Cognitive Strategies in Improving Comprehension of Students with Mathematical Disability. The study revealed that significant difference was found in the post test score of experimental and control group. From the results of the study it can be concluded that cognitive intervention has positive impact on the numerical abilities of students with mathematical disability.

H. Lee Swanson (2015) studied Cognitive strategy interventions improve word problem solving and working memory in children with math disabilities. The study revealed that Three major findings emerged: (1) strategy instruction facilitated solution accuracy but the effects of strategy instruction were moderated by WMC, (2) some strategies yielded higher post-test scores than others, but these findings were qualified as to whether children were at risk for MD, and (3) strategy training on problem solving measures facilitated transfer to working memory measures. The main findings were that children with MD, but high WM spans, were more likely to benefit from strategy conditions on target and transfer measures than children with lower WMC. The results suggest that WMC moderates the influence of cognitive strategies on both the targeted and non-targeted measures. Marjorie.M (2011) Studied Effects of Cognitive Strategy Instruction on Math Problem Solving of Middle School Students with Learning Disabilities. The results indicated that students who received the intervention $(n=319)$ showed significantly greater growth in math problem solving over the school year than students in the comparison group $(n=460)$ who received typical classroom instruction. Moreover, the intervention effects did not differ for students with learning disabilities, low-achieving students, and average-achieving students. Thus, the findings were positive and support the efficacy of the intervention when implemented by general education math teachers in inclusive classrooms.

\section{METHODOLOGY}

Purposive sampling method was used to select schools for the study. A sample of 100 academically low achieving students studying in the grade 3 students were selected from siddipet government primary schools belonging to Telangana. 8-10 age group students were selected for this study. From 100 children 50 formed the experimental group and 50 control groups. Arithmetic learning skills were tested through Grade level assessment device for Grade-III students developed by Jayanthi (1997). Six months' cognitive intervention strategies were implemented to enhance the mathematical performance of primary school students.

\section{RESULTS AND DISCUSSION}

It should be noted that GLAD test was used to measure mathematical problems. This test was administered to two Government primary school students in the 3rd grade of primary school students.

Table: 1 Frequency And Percentages On Mathematical Performance Of Primary School Students

\begin{tabular}{|l|l|l|l|l|l|l|l|}
\hline S.No & Gender & \multicolumn{4}{|l|}{ Mathematical performance } \\
\hline & & High & \multicolumn{2}{l|}{ Average } & \multicolumn{2}{l|}{ Low } \\
\cline { 3 - 8 } & & n & $\%$ & n & $\%$ & N & $\%$ \\
\hline 1 & Boys & 13 & 26 & 14 & 28 & 23 & 46 \\
\hline 2 & Girls & 11 & 22 & 14 & 28 & 25 & 50 \\
\hline
\end{tabular}

It was evident from the table -1 that fifty per cent of primary school girls students scored low on mathmatical performance and remaining thirty per cent of boys and girls were in moderate category. This infers that low score on mathmetical performance refers to primary school students have poor mathmatical skills in number additions, substitutions, reversals in writing, reading, recalling numbers and difficulty with abstract concepts of time and direction. Students with mathematical difficulties and $\mathrm{LD}$ often struggle with word problems because they (a) lack understanding of the language within the problems.

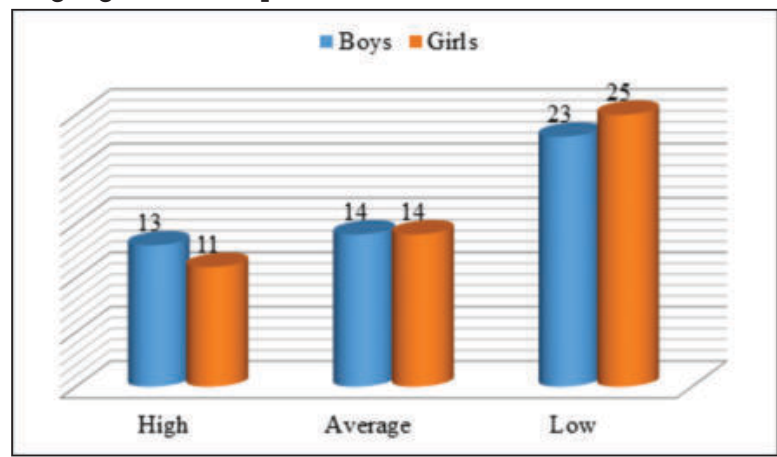

Fig: 1 Mathematical Performance Of Primary School Students

Table: 2 Mean Differences Between Control And Experimental Group On Mathematical Performance Of Primary School Students.

\begin{tabular}{|l|l|l|l|l|}
\hline Group & Term & Mean & t value & p value \\
\hline Control Group & Pre-test & 15.68 & -0.954 & 0.3 NS \\
\cline { 3 - 5 } Experimental Group & & 16.1 & & \\
\hline Control Group & Post-test & 15.68 & -3.453 & $0.001^{* *}$ \\
\hline Experimental Group & & 17.2 & & \\
\hline
\end{tabular}

$* * \mathrm{p}<0.01$ level of significance.

Table-2 represents mean scores of pre-test and post-test scores of control and experimental group of primary school students in Telangana villages. There were no statistically significant differences between pre-test scores of control and experimental groups. Intervention results revealed that there was significant difference between post scores of control and experimental groups which means that cognitive intervention strategies helped them to improve their mathematical performance of primary school students. Cognitive strategy 
instruction consists of teaching cognitive and metacognitive strategies to enhance learning and improve performance (Montague etal.,2011).

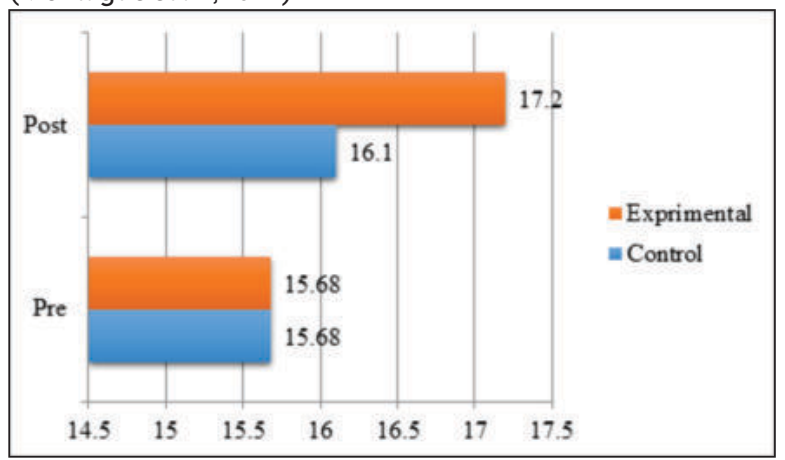

Fig: 2 Mean Differences In Mathematical Performance Of Primary School Students Before And After Intervention

\section{CONCLUSION}

Mathematical problem-solving abilities are necessary for academic success. Mathematics difficulties in solving word problems can be a "major impediment for students' future success in any math related discipline. The study results revealed that there was no significant difference between pre-test score of control and experimental group of primary school student. Intervention results showed that there was significant difference between post test scores of control and experimental group of primary school students. It can be concluded that cognitive intervention strategies to enhance learning and improve performance of grade 3 level students. Cognitive strategies helped students to focus on the linguistic and semantic information of the problem's structure (e.g., join, separate problems) and provides a way for solving the problem, thus potentially increasing student understanding of the meaning of the problem and ability to solve the problems.

\section{REFERENCES}

1. Benavides.V.S (2020). Effectiveness of digital-based interventions for children with mathematical learning difficulties: A meta-analysis. Computers \& Education, 157, Article 103953. https://doi.org/10.1016/j.compedu. 2020.103953

2. Kathleen.H.P et.,al (2015) Cognitive Strategy Instruction for Teaching Word Problems to Primary-Level Struggling Students. Intervention in School and Clinic.Vol.50(5) 291-296.

3. Radhika. S and Kavitha.K (2017) Effect of Cognitive Strategies in Improving Comprehension of Students with Mathematical Disability. Studies on Home and Community Science 1 1(1):32-35.DOI:10.1080/09737189.2017.1340121.

4. Fatimah.S et.,al (2020) Students' Mathematical Problem-Solving Ability Based On Teaching Models Intervention And Cognitive Style. Journal on Mathematics Education Volume 1 1, No. 2, May 2020,pp. 209-222-209.

5. Varela.S.B (2020) Effectiveness of digital-based interventions for children with mathematical learning difficulties: A meta-analysis. Computers \& Education.Vol 157.103953

6. Sarah R.P et., al (2019) A Synthesis of Elementary Mathematics Interventions: Comparisons of Students with Mathematics Difficulty with and Without Comorbid Reading Difficulty.Volume:53 issue:4,page(s):244-276

7. Maryam.P (2018) Mathematics Performance of the Primary School Students: Attention and Shifting. Journal of Education and Learning 7(3):117. DOI: $10.5539 /$ jel.v7n3pl17.

8. H. Lee Swanson (2015) Cognitive strategy interventions improve word problem solving and working memory in children with math disabilities. Front Psychol; 6: 1099.doi: 10.3389/fpsyg.2015.01099

9. Marjorie M (2011) Effects of Cognitive Strategy Instruction on Math Problem Solving of Middle School Students with Learning Disabilities. Learning Disability Quarterly 34(4):262-272. 